\title{
Solid Pulmonary Nodule
}

National Cancer Institute

\section{Source}

National Cancer Institute. Solid Pulmonary Nodule. NCI Thesaurus. Code C138143.

A pulmonary nodule with well-defined marg ins and homogenous soft-tissue attenuation on CT scan examination. 